\title{
Development of a Mathematical Language Scale in Fraction Teaching (MLSFT)
}

\author{
Belgin BAL INCEBACAK* \\ Primary Education Department, Ondokuz Mayis University, Samsun, Turkey \\ ORCID: 0000-0003-4643-8051
}

Esen ERSOY

Mathematics and Science Education Department, Ondokuz Mayis University, Samsun, Turkey ORCID: 0000-0002-7594-8838

Article history

Received:

01.03.2021

Received in revised form: 18.07.2021

Accepted:

03.08.2021

Key words:

\section{Fractions teaching,}

Mathematical language,

Reliability,

Scale development,

Validity.
This study aims to develop a valid and reliable measuring instrument that can measure the level of mathematical language used by students and their teachers during the teaching of fractions to fourth-grade primary school students. This study is a methodological validity and reliability study. In total, 999 students from fourteen different secondary schools were separated into two other sampling groups, where they participated in the sample of the survey for Exploratory Factor Analysis (EFA) and Confirmatory Factor Analysis (CFA). These stages are identified as the item pool stage, the testing validity of scope stage (expert opinion stage), the factor analysis stage (construct validity), and the reliability stage. Mathematical language scale in the teaching of fractions consists of the student approach, the use of fraction language and the use of symbols, and the written expressions of sub-dimensions. The exploratory factor analysis method (EFA) shows that the instrument can be built on three factors. It is also confirmed by the confirmatory factor analysis (CFA). It can be accepted according to NFI indexes. As a result, the mathematical language scale is found to be valid and reliable in fraction teaching. To this end, it can be stated that the MLSFT scale can be used in fraction teaching for elementary school students to reveal their abilities and the skills of teachers in terms of mathematical language used.

\section{Introduction}

Language helps us to express our ideas and opinions and to communicate. Çalıkoğlu Bali (2002) stated that the language is composed of words and that the words represent labels of specific concepts and ideas. Additionally, he said that due to the fact that language is a social dimension, it is required to be strengthened in classroom communication. Ellerton and Clarkson (1996) indicated that social, cognitive, cultural, linguistic, and affective factors in mathematics courses affect the development of language. Mathematics should be taught in its language because every concept in mathematics has its importance. Çalıkoğlu Bali (2002)

\footnotetext{
* Correspondency: belginbal33@gmail.com
} 
stated that every new concept in mathematics represents a new word. Since every new word introduces a new idea, it is necessary to teach the mathematical terms used in mathematics classes correctly.

Sinanoğlu (2000) indicates that teaching language with mathematical concepts can lead to more permanent and meaningful learning. It will provide learning by the brain that will be processed within the logic rules. Toptaş (2015) emphasized that it is important to teach mathematical language at the age of elementary school when the development of language has started. Orton and Frobisher (1996) noted that mathematical language should be used in the learning-teaching process. Moreover, they explained it by a case study. They indicated that we assume the words used in mathematics as the ideas in our minds. However, they expressed that it cannot always be accurate and it could be a sign we cannot communicate properly. Accordingly, Toptaş (2015) concluded that if a student is asked to explain the geometric shape of a square. The student answers as "square is a place in a city where people gathered", it is understood that the student linked the square term used in daily life with the square term used in mathematics and did not understand it correctly. Raiker (2002) asserted that the mathematical language progressed spirally. The exact meaning of the words has to be taught correctly to provide a solid basis for the development of mathematical thinking. The understanding of the mathematics of the students has an important role in the formation of mathematical language (Gawned, 1990). Therefore, classroom teachers should pay particular attention to the use of mathematical language in classroom discussions, especially in mathematics classes, and should allow students to express the mathematical problems in written and verbal forms. The NCTM (2000) (National Council of Teachers of Mathematics in the US) argues that students should have the ability to express problem-solving methods in written and verbal forms. One of the general objectives of mathematics education in the report of NCTM (1989) is that 'the student must learn to speak mathematically'. Students are expected to use the mathematical language in classroom dialogs. They will understand the language better if they participate in discussions on creating and solving a problem.

It is known that fractions are among the subjects that even middle school students have difficulty understanding. In their studies, Sowder and Wearne (2006), Wearne and Kouba (2000) stated that students had poor understanding of fractions and often lacked information. The NMAP (2008) study found that students in particular experienced difficulties in fractional calculations, deity numbers, and percentage concepts. The foundations of these areas are also given at the elementary school level. For this area, the need arises to educate students in a way that is more quality and better understood by them. NCTM (2006) stated that the concept of basic fraction started in the 3rd grade of primary school and was especially understood at the 4th-grade level. When the fractions are not well understood at this age level, it is thought that students at advanced levels have difficulty understanding this subject. Fraction teaching is an essential subject for mathematics. When we looked at the studies, it was determined that the students failed and had difficulty with the fractions.

In this respect, it is thought that working in this field will contribute to the field due to the limited work at the primary school level for the subject of fractions.

A study by Otterburn and Nicholson (1976), conducted by teachers and students, found that students know mathematical terms. Teachers often find it difficult to explain and express mathematical terms they often use. It is shown that teachers do not use mathematical terms correctly and effectively. Each new mathematical concept should be presented in a good and correct manner, and the students can grasp the new ideas with different meanings. Orton and 
Frobisher (1996) indicated that students have difficulty with verbal problems. The reason is associated with the importance given to the language of mathematics. When the studies on language use in mathematics teaching are analysed, it is seen that samples composed of undergraduate students (e.g., Çalıkoğlu Bali, 2002; Soylu and Aydın, 2006; Aydın and Yeşilyurt, 2007; Gökkurt, Soylu and Gökkurk, 2012; Doğan and Güner, 2012; Toptaş, 2015), secondary school students (e.g., Yüzerler and Doğan, 2012; Aydın and Özmen, 2012) and high school students (e.g., Kaya and Keşan, 2012; Ev Çimen, 2012; Güneş and Gökçek, 2013). No study has been found in the field of primary schools. Teachers understand the significance of language as a tool for coaching mathematics. They can shape and guide conversations using language to help students further their development of mathematical concepts. Moseley (2005) states that the implications of the instructor's interpretations of basic mathematical terminology combined with their use of everyday language may influence their ability to see opportunities for teaching mathematical concepts not only in the context of an explicit math lesson but throughout the broader early childhood curriculum. Further, in elementary school children, mathematical language is a strong predictor of numeracy skills even when accounting for a range of cognitive covariates and prior numeracy achievement (Toll and Van Luit, 2014). Moreover, knowledge of mathematics language has been surmised to be critical toward the success of early mathematics curricula (Chard et al., 2008; Clements and Sarama, 2011). Even the NCTM (2006) indicates the importance of high-quality mathematics language in teaching: "Children need introductions to the language and conventions of mathematics, at the same time maintaining a connection to their informal knowledge and language. They should hear the mathematical language being used in meaningful contexts. Young children need to learn words for comparing and for indicating position and direction at the same time they are developing an understanding of counting and number words" Yet, even with the growing body of evidence supporting the importance of mathematical language for numeracy development; it is rarely a focus in early numeracy research. For this purpose, the development of the fractional language scale in mathematics teaching was accepted to overcome the shortcomings in the literature.

\section{Methods}

The fundamental research type is used to develop a scale to determine the level of mathematical language use of students and mathematics teachers in mathematics classes with the "Mathematical Language Scale for Fractional Teaching (MLSFT)". Fundamental research aims to generate knowledge on a particular subject and theory (Singh, 2006; Kothari, 2004). In this regard, Büyüköztürk (2002) and Child (2006) stated that the number of variables observed should be five times the number of variables observed when calculating the sample size. Kline (2005) noted that the sample should be ten times the number of substances but emphasized that this number should not be less than two hundred. Andrew, Pedersen, and McEvoy (2011:204) stated that there should be 20 people for each item. Still, in cases where this number is not reached, the analysis will be correct by taking ten people if the participant/subject is more minor. Osborne and Costello (2004) according to Even if the sample of 1000 people or the 20:1 participant/item ratio is studied, unrealistically good factor analysis can be found. Since the calculations of the sample size of the language scale in the fraction teaching are composed of 28 items, it is considered that at least 560 students should be included. In other words, 20 students for each item number. Thirty-eight students left one page of the two-page scale blank, and those scales were excluded. Comrey and Lee (1992), 100 weak in sample size, 200 medium, 300 good, 500 very good and described 1000 as excellent. In total, 999 students were included in the sample. Information on the subjects included in the sample group has shown in Table 1. 
Table 1.Descriptive Statistics Related to the Working Group of Scale Development

\begin{tabular}{lllll}
\hline Analysis & Schools & Female & Male & Total \\
\hline EFA & Public Schools & 210 & 204 & 579 \\
& Religious Vocational Schools & 38 & 35 & \\
& Boarding Regional Primary Schools & 47 & 45 & \\
CFA & Public Schools & 134 & 135 & 420 \\
& Religious Vocational Schools & 30 & 30 & \\
& Boarding Regional Primary Schools & 46 & 45 & \\
Total & & 505 & 494 & 999 \\
\hline
\end{tabular}

In total, 999 students from fourteen different secondary schools were separated into two other sampling groups, where they participated in the sample of the study for Exploratory Factor Analysis (EFA), and Confirmatory Factor Analysis (CFA). The working group includes a total of 9 schools. These schools are public schools, religious vocational schools, and boarding regional primary schools. The number of scales applied in public schools is 683,133 in boarding regional primary schools, and 183 in the religious vocational secondary schools. While the number of female students is 505 , the number of male students is 494 . The number of students leaving the test blank was not included in the table. Twenty-one students from public schools, 12 students from the boarding regional primary schools, and 5 students from the religious vocational secondary schools were not included in the sample group because they left one page of the two-page scale blank. The data was obtained by the easy-to-access sampling method. Random class separation was made for CFA and EFA, and data was not collected for CFA from the class where data was collected for EFA when collecting data from schools. Shapiro-Wilks test and Kolmogorov-Smirnov test checked whether the data showed normal distribution $(\mathrm{df}=999=.919)$.

\section{Data Analysis}

It is seen that scale development studies consist of four stages in the literature. According to Karasar (2009), these stages are identified as the item pool stage, the testing validity of scope stage (expert opinion stage), the factor analysis stage (construct validity), and the reliability stage. In the course of developing a language scale in fraction teaching, exploratory factor analysis (EFA) and confirmatory factor analysis (CFA) was performed to determine the scale's validity. While the exploratory factor analysis studies were carried out in the IBM-SPSS 20.0 package program, confirmatory factor analysis studies were carried out in the Amos 8.6 package program. Moreover, item-test score correlations were calculated by internal consistency coefficient Cronbach Alpha for reliability. Data of the study were analyzed using IBM-SPSS 20.0 and Amos 8.6 package programs. To reveal the factor structure of the Language Scale in Fractional Teaching (Walkey and Welch, 2010), the maximum rotation (varimax) technique was selected from the orthogonal rotation methods, taking into account the clarity meaning the principal component analysis within factoring. The study of the items was made by the analysis method based on correlation. The Pearson correlation coefficient was used to calculate the total test correlations of the item. Murphy and Davidshofer (1998) and Walsh and Betz (1995) stated that exploratory factor analysis should determine the factor structure. Gable (1986) and Tabachnick and Fidell (2001) indicated that varimax rotation should be carried out while performing exploratory factor analysis. Büyüköztürk (2011) recommended that the minimum difference between the two high values should be 0.10 in exploratory factor analysis. He also stated that in case of entering more than one factor, the difference between the loadings should be 0.10. Yavuz (2005) indicated that if the difference between the two factors is less than 0.10, these items overlap. The researcher can determine items loaded under which factors by explanatory factor analysis (Coakes, 
2005) and observe the data validation process of the model generated by confirmatory factor analysis (Noar, 2003).

The models were tested by confirmatory factor analysis according to the results of the exploratory factor analysis. Then, the goodness of fit indexes related to the model was examined. Following the exploratory factor analysis, confirmatory factor analysis was performed to test the model. Chi-square $\left(\chi^{2}\right), \chi^{2}$ / sd, RMSEA, RMR, GFI, IFI, NNFI, NFI, and AGFI goodness of fit indexes of the model were examined by testing with confirmatory factor analysis. Şimşek (2007) defined confirmatory factor analysis as a type of structural equation modeling (SEM). Structural equation modeling experienced a development process as Regression analysis, PATH analysis, Confirmatory factor analysis, and Structural equation modeling. Karl Joreskog, who fully developed the confirmatory factor analysis in 1960, wrote an article using the first confirmatory factor analysis in 1969 (Schumacker and Lomax 2004: 498; Y1lmaz and Çelik; 2009: 2).

\section{Results}

According to Karasar (2009), there are four stages in the development of scale studies, and they are identified as the item pool stage, the testing validity of scope stage (expert opinion stage), the factor analysis stage (structure validity), and the reliability stage.

\section{Item Pool Stage}

In the first stage of the development of the scale, the relevant literature was reviewed. To develop the mathematical language scale in fraction teaching, articles and theses written in this area were analyzed. All levels of language used in a mathematics course by teachers and students during mathematical operations were defined. Afterward, the most repeated sentences were noted. The most repeated sentences were transformed into question items, and an item pool was formed. Items were prepared as questions to be evaluated by an expert. Besides, experts were consulted to for them to decide whether the items fit and to indicate how it should be expressed if the item does not fit. A total of 35 item pools was determined.

\section{The Stage of Testing Validity of Scope (Expert Opinion Stage)}

Prepared expert forms were sent to 3 mathematics teachers, two classroom teachers, and two academicians, and their opinions on these items were consulted. These experts made suggestions to remove similar items and to correct vaguely understood sentences. Afterward, the scale was given its final shape. The first questionnaire of the scale consists of 35 items in total. Seven lecturers who are experts in mathematics education were further consulted about their opinions on these items. After the opinions of the experts were analyzed, the items that were thought to be above the level of the students, similar items, and items that student had difficulty in expressing and understandings were removed. As a result, a test questionnaire consisting of 28 items was formed. Analyses were performed on this trial questionnaire. For example, the items "In mathematics teaching, our teacher uses mathematical terms correctly" are arranged as "Our teacher is constantly using mathematical terms (eg, point, circle, plus, minus) while teaching fractions." after expert opinion. The item "The subject of fractions in daily life can be expressed mathematically." is arranged as "Some of the terms are often used in everyday life, so students do not have any problems understanding this subject."

"I'm having trouble understanding the mathematical language about fractions" the substance was removed from the scale after expert opinion. 


\section{Factor Analysis Stage (Structure Validity) and Reliability}

The Kaiser-Meyer-Olkin (KMO) value was determined as 0,935 in the analyses made to determine the compliance of the data obtained from applying a 28-item trial questionnaire to the factor analysis. If the KMO value is above 0.90, it can be interpreted as the sample size is the best fit (Hutcheson and Sofroniou, 1999). Initially, exploratory factor analysis was performed after a confirmatory factor analysis was conducted during the factor analysis stage. Moreover, the retest reliability coefficient of the questionnaire was calculated for reliability. The details of the A-analyses made during the process (Exploratory Factor Analysis, Reliability Stage, Confirmatory Factor Analysis, PATH Diagram) are shown below.

\section{Exploratory Factor Analysis (EFA)}

Following the application of the first questionnaire of the scale to 579 fifth-grade students, the data were transferred to the SPSS program. In this study, reversed-coded items were converted to new values before the analysis. Exploratory factor analysis and varimax rotation process were performed. To perform an exploratory factor analysis, the compliance of the data for factor analysis was examined by using the Kaiser-Meyer-Olkin test and Bartlett's sphericity test. It is found that these calculated scores are at a level of .878 for Kaiser-Meyer-Olkin Coefficient (KMO) and .000 for Bartlett's sphericity test. Since these calculated values have been considered significant, the $\mathrm{H} 0$ hypothesis of the "universe correlation matrix is unit matrix" was rejected. It has been found that applying factor analysis to the sample size was proper. Tabachnick and Fidell (2001) reported that if Bartlett's sphericity test value is smaller than .05 , the data set has a multivariate normal distribution and is suitable for factoring. After these values were calculated, exploratory factor analysis processes have been started. Tabachnick and Fidell (2001) stated that the factor loadings should be greater than .30 in factor analysis, and analysis should be conducted with items bigger than 1. As Büyüköztürk (2011) indicated, two items with loading values below .10 were excluded from the scale. Factor loadings were rotated according to varimax rotation, and 3 factors with an Eigenvalue greater than one and their variances were found. Cronbach's Alpha coefficient calculated the reliability of the entire scale and each factor.

Following the exploratory factor analysis, findings of reliability, item-total test correlation, and factor analysis results are given in Table 2 .

Table 2. The Results of Reliability, Item Total Test Correlation and Factor Analysis of the Language Scale Trial in Fractional Teaching

\begin{tabular}{|c|c|c|c|c|c|c|c|}
\hline \multicolumn{8}{|c|}{ Component Matrix } \\
\hline NO & 1 & 2 & 3 & 4 & 5 & 6 & 7 \\
\hline DM26 & ,734 & & ,322 & & & & \\
\hline DM15 & ,715 & & & & & & \\
\hline DM20 & ,709 & & & & & &, 326 \\
\hline DM09 & 694 & & & & & & \\
\hline DM13 & 693 & & & & & &,- 333 \\
\hline DM14 & 678 & & ,302 & & & & \\
\hline DM17 & 651 & & & & & & \\
\hline DM28 & 646 & &, 313 & & & & \\
\hline DM12 & 613 & & ,436 & & & & \\
\hline DM10 & 604 & & &, 512 & & & \\
\hline M016 &,- 602 & ,539 & & & & & \\
\hline M004 &,- 546 &, 525 & & & & & \\
\hline M007 &,- 530 & ,507 & & & ,342 & & \\
\hline M008 &, 514 & & &,- 300 & &, 314 & \\
\hline M019 & ,444 & ,329 &,- 335 & & & & \\
\hline
\end{tabular}




\begin{tabular}{lllllll}
\hline M024 &, 426 &, 331 & & &, 336 & \\
M025 &, 417 &, 395 & &,- 305 & & \\
M021 &, 389 &, 367 &,- 325 & & & \\
DM23 &, 438 &,- 563 & & &, 349 & \\
DM11 &, 350 &,- 547 & & &, 302 & \\
DM06 &, 370 &,- 517 & & & \\
& & Eigenvalue & Variance & Cronbach's Alpha & & \\
& F1 & 7,671 & 27,396 & & & \\
& F2 & 3,286 & 11,736 & & & \\
Factor no & F3 & 2,249 & 8,032 & & \\
& F4 & 1,662 & 5,937 & .878 & & \\
& F5 & 1,451 & 5,184 & & & \\
& F6 & 1,150 & 4,108 & & & \\
& F7 & 1,033 & 3,689 & & & \\
\hline
\end{tabular}

Following the analysis of Table 2, it is observed that the internal consistency coefficient of the test questionnaire is .878 , and seven factors having larger than the Eigenvalue of 1 are formed. When the eigenvalue of the first factor is analysed $(7,671)$, it is found that the first factor is two times bigger than the eigenvalue of the second factor $(3,286)$. The first factor accounts for $27,396 \%$ of the variance, while the second factor accounts for $11,736 \%$ of the variance. It is seen that the 2,249 variance of the third-factor value is 8,032 . When factors having an eigenvalue larger than one are taken into account to calculate the number of factors, the scale seems to be having 7 factors. The fourth, fifth, sixth, and seventh-factor loadings are close to each other. In other words, it was decided to use the rotation method for a clear view of factor loading distribution by analysing the latter one more time. Figure 1 shows the eigenvalues by ScreePlot analysis.

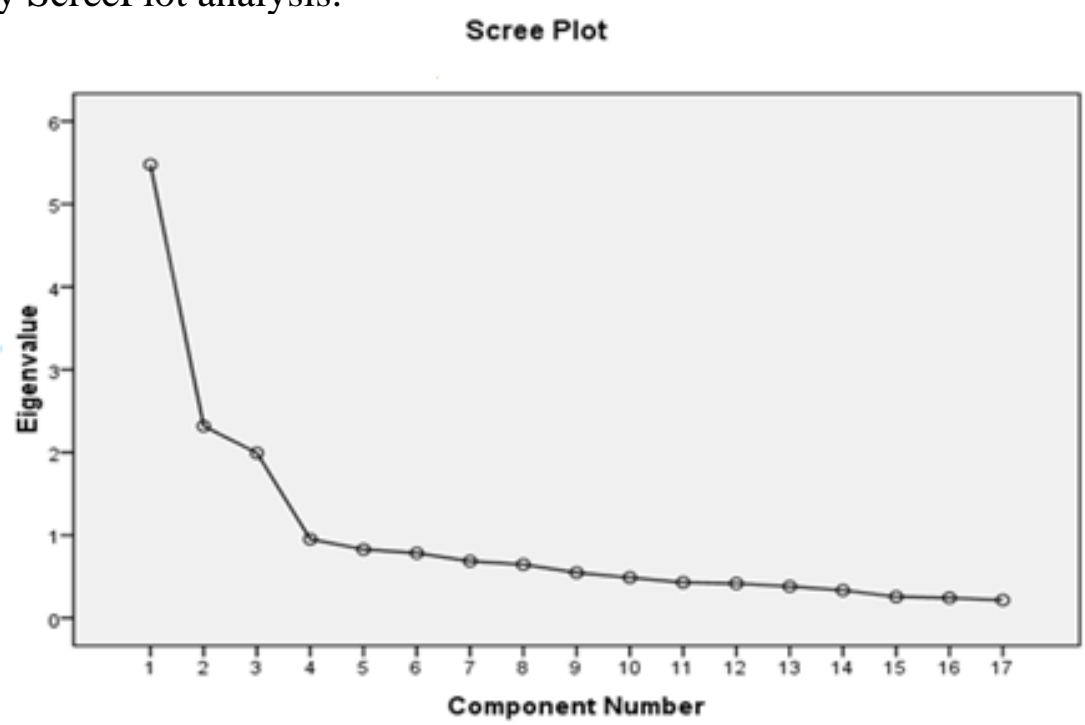

Figure 1. Factor Eigenvalues of Scale Plot

It is shown in Figure 1 that the eigenvalues of 7 factors are larger than 1 . It is necessary to examine the distribution of factors after the number of factors is determined. Varimax, an orthogonal rotation method, is used to identify the factors having the strongest correlations of the items due to the easiness of interpretation and the frequency of use of the varimax (Yiğit and Kurnaz, 2010).

To determine which type of rotation to be selected for use, the correlations between the factors were examined, and no relation between the factors was found. Therefore, it was decided to use the Varimax orthogonal rotation technique. Exploratory factor analysis studies 
based on the Varimax rotation method revealed that the scale had a one-factor and threecomponent structure. Factor values and total test correlations of items on factors loadings of the scale rotated by varimax rotation method, factor structure, and reliability coefficient are included in Table 3.

Table 3. Table of Factor Loadings Rotated According to Varimax Rotation

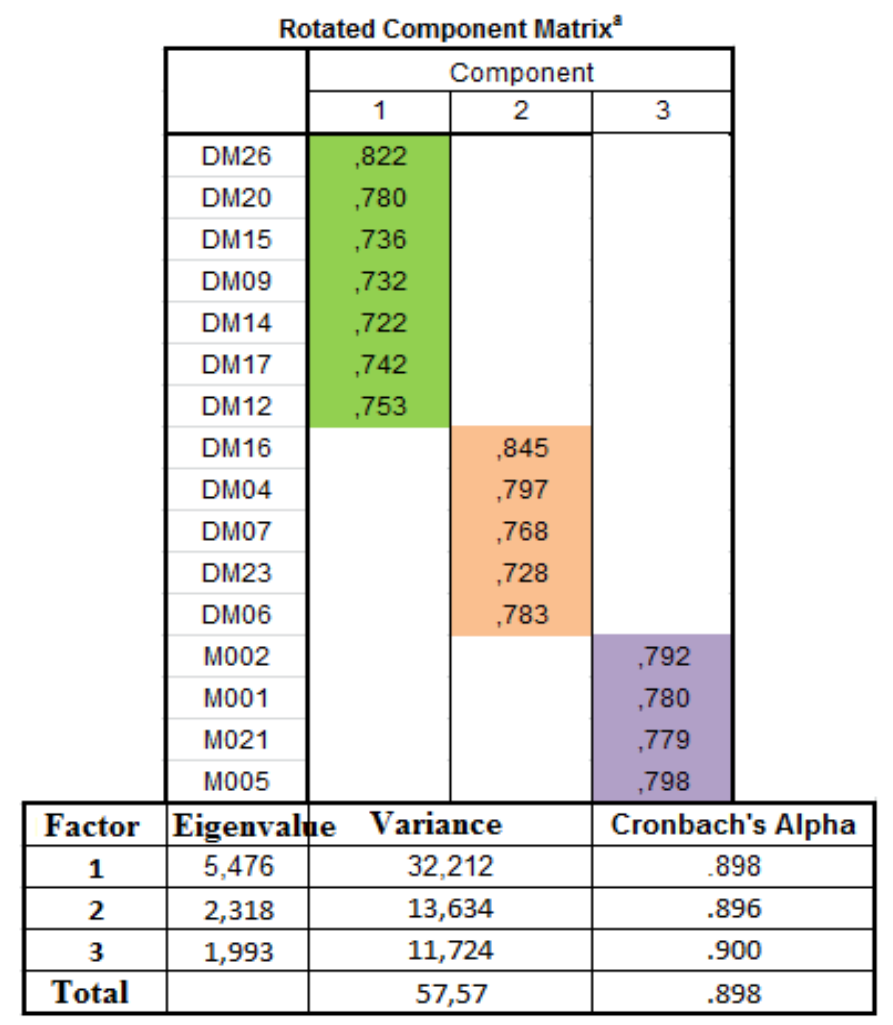

According to the results of Table 3, it was found that 11 items from the original 28 items were not suitable after varimax rotation, and therefore 11 items were excluded from the scale. The structure formed by the remaining items became a structure of 3 factors having an eigenvalue larger than 1. It has been observed that its variance was found to be $57.57 \%$. Factor 1 accounts for 32,212\%, factor 2 accounts for 13,634 and factor 3 accounts for 11,724 of the total variance. The internal reliability coefficient of each factor was determined as $.898, .896$, and .900 , and the reliability coefficient (Cronbach's Alpha) of the whole scale was found to be .898. Sipahi and Yurtkoru, Çinko (2010); Büyüköztürk (2011) emphasized that reliability of the scale should be determined by Cronbach Alpha value and have the value of .70 and above. Tezbaşaran (1997), Şeker and Gençdoğan (2006), Başol et al., (2008) indicated that it was enough for the reliability coefficient to be close to 1. For Alfa, Tekindal (2009) qualified under .60 as unacceptable, $.60-.65$ as undesirable, $.65-.70$ as acceptable, $.70-.80$ as quite good, $.80-.90$ as very good, and .90 and above as great.

\section{Reliability Stage}

The test-retest reliability coefficient was calculated within the framework of the reliability study of the language scale in fraction teaching. 60 5th grade secondary school students were included in the study to determine the test-retest consistency values of the scale. The scale was applied to the working group twice at a 15-day interval. The Pearson correlation coefficient value between the first and the last measurements was calculated. 
Firstly, the Shapiro-Wilks and Kolmogorov-Smirnow tests were analyzed to determine the normality of the initial and final measurement distributions. According to the analysis results, the first measurements were calculated as .963 for the Shapiro-Wilks test and .901 for the Kolmogorov-Smirnow test. When the values were examined, it was found that the data were normally distributed. Additionally, the correlation between the initial measurement points and the final measurement points was positive at a medium level. $(\mathrm{r}=.494, \mathrm{p}<.05)$. Accordingly, the test-retest reliability of the language scale of fraction teaching in the study was considered high.

The remaining 16 items were distributed as 7 items to factor no. 1, 5 items to factor no. 2, and 4 items to factor no. 3. It was found that the components generally showed a significant positive correlation with each other and, with the total score. These findings are accepted as indicators for the scale having a single-factor, three-component structure. At the end of the removal process, 16 items have remained. The distribution of the items according to the factors is given below in Table 4:

Table 4. Items under factors / components

\begin{tabular}{|c|c|c|}
\hline Factor & Theme & Item \\
\hline 1 & 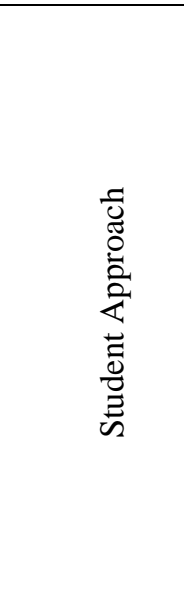 & $\begin{array}{l}\text { DM26 Using language meaning symbols related to fractions, topics, and fraction } \\
\text { expressions does not help for a better understanding of the next topics. } \\
\text { DM20 the expressions related to fractions such as division line, denominator, and } \\
\text { numerator do not have to be written. } \\
\text { DN14 When dealing with fractions, I can make operations or solve problems without } \\
\text { knowing the meaning of the symbols of the denominator and the numerator. } \\
\text { DM09 It is not required to use a fluent and descriptive language of expression in the } \\
\text { subject of fractions, as in the case of ratio and proportions, and in other subjects in } \\
\text { mathematics. } \\
\text { DM15 I can understand the subject even if the teacher does not use the mathematical } \\
\text { language of fractions. } \\
\text { DM17 Written assignments do not help the teaching process of fractions. } \\
\text { DM12 Students can use symbols related to fractions and decimal fractions while } \\
\text { answering questions / in daily life without knowing their meaning them. }\end{array}$ \\
\hline 2 & 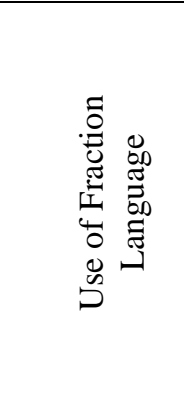 & $\begin{array}{l}\text { DM16 I can use a comma in decimal fractions to specify digit value names of the } \\
\text { proper and decimal parts. } \\
\text { DM04Some of the terms used infractions are often used in everyday life, so students } \\
\text { do not have any problems understanding this subject. } \\
\text { DM07 The use of commas in decimal fractions must be expressed both verbally and } \\
\text { in written form. } \\
\text { DM23 My teacher does not give importance to express the meaning of the symbols of } \\
\text { "fractions" that we do not know in written form. } \\
\text { DM06 When ordering fractions, there is no need to study it verbally again since the } \\
\text { symbols are clear enough. }\end{array}$ \\
\hline 3 & 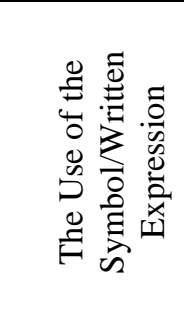 & $\begin{array}{l}\text { M002 Our teacher constantly uses mathematical terms (eg, point, circle, plus, minus) } \\
\text { while teaching fractions. } \\
\text { M001 Our teacher is constantly using mathematical terms (eg point, circle, plus, } \\
\text { minus) in mathematics teaching. } \\
\text { M021 It should be allowed to express the problem in written form while solving a } \\
\text { fraction problem. } \\
\text { M005 My teacher explains the symbols for the bigger than and smaller than used } \\
\text { infractions in written form. }\end{array}$ \\
\hline
\end{tabular}

Following an analysis of the distribution of the items in the scale according to the components, it is observed that the first component is composed of 26th, 20th, 14th, 9th, 15th, 17 th, and 12th items. This component is called the student approach because the items in this 
component consist of items including students' evaluations on fractions. The second component is composed of 16th, 4th, 7th, 23rd, and 6th items. This component is called the fractional language use component because students use expressions and language when performing fractional operations. The third component consists of $1 \mathrm{st}$, 2nd, 5th, and $21 \mathrm{st}$ items. This component is referred to as symbol use-written expression because items contain symbols and written expressions used in mathematics and especially in fraction teaching.

\section{Confirmatory Factor Analysis (CFA)}

The most fundamental characteristic of structural equilibrium modeling is purely theory-based (Çapık, 2014: 197). While the analysis in the exploratory factor can be performed without a theoretical basis, the researcher is required to have a theory in the confirmatory analysis. Confirmatory factor analysis is a method of analysis used in the development of measurement models. Myers (2000) identified confirmatory factor analysis as the process of revealing hidden variables of a pre-established model.

The normal values and acceptable values of the goodness of fit indexes used in confirmatory factor analysis are shown in Table 5.

Table 5. The Goodness of Fit Indexes and Its Normal Values Used in Confirmatory Factor Analysis

\begin{tabular}{lll}
\hline Indexes & Normal Values & Acceptable Values \\
\hline$\chi^{\prime}$ 'p' Values & $\mathrm{p}>0.05$ & - \\
$\chi 2$ /sd & $<2,5$ & $<5$ \\
GFI & $>0.95$ & $>0.90$ \\
AGFI & $>0.95$ & $>0.90$ \\
CFI & $>0.95$ & $>0.90$ \\
RMSEA & $>0.05$ & $<0.08$ \\
RMR & $>0.05$ & $<0.08$ \\
SRMR & $>0.05$ & $<0.08$ \\
\hline
\end{tabular}

Here is Goodness-of-fit Index (GFI), Adjusted Goodness-of-fit Index (AGFI), Comperative Fit Index (CFI), Root Mean Square Error of Approximation (RMSEA)

Root Mean Square Residuals (RMR) and Standardized Root Mean Square Residual (SRMR). The $\mathrm{p}$-value is considered while conducting $\chi^{2}$ analysis in the study. If the calculated result is 0.05 , it is interpreted that the fittingness is significant when the value of $\mathrm{p}$ is below 0.05 . If the $\chi 2$ / df ratio calculated according to the model is less than 2.5, it is the perfect fit. If it is less than 5, the fit is acceptable (Kline, 2005; Sumer, 2000). Marsh and Hocevar (1988) stated that if GFI and AGFI values are higher than 0.90 and RMSEA values are lower than 0.05 , and it indicates the model-data fit. If GFI is above 0.90, AGFI is above 0.90, and RMR and RMSEA values are less than 0.10, it is considered as the lower limit of acceptance for model data fittingness (Munro, 2005, Simsek, 2007, Schumacker and Lomax, 2010; Wang and Wang, 2012).

According to Brown and Cudeck (1993), fit indexes are considered Goodness of Fit Index (GFI): as acceptable for above .85 and perfect for above, .90; Comparative Fit Index (CFI): as acceptable for above .95, and perfect above .97; Incremental Fit Index (IFI): as acceptable above 90, and perfect above 95; Normed Fit Index (NFI): as acceptable above .90, and perfect above .95; Non-normed Fit Index (NNFI): as acceptable above .90 and perfect above .95; Adjusted Goodness of Fit Index (AGFI): as acceptable above .85 and perfect above .90; Root Mean Square Residuals (RMR): as acceptable between .050 -.080 and perfect between .000 - 
.050; Parsimonious Fit Index (RFI): as acceptable above .90 and perfect above .95; Root Mean Square Error of Approximation (RMSEA): as acceptable between $.050-.080$ and perfect between.000 -0.50.

Confirmatory factor analysis (CFA) was applied to determine the accuracy of the 3-factor model which was identified by exploratory factor analysis. Values of RMSEA, GFI, CFI, AGFI, NFI, and Chi-square fit tests were found by analyzing the model's compliance indexes. The results for these values are shown in Table 6:

Table 6. Results of the Confirmatory Factor Analysis (CFA)

\begin{tabular}{llll}
\hline Above & Perfect Above & Acceptable Above & Model Value \\
\hline RMSEA & $0<\mathrm{RMSEA}<0.05$ & $0.05<\mathrm{RMSEA}<0.10$ &, 061 \\
NFI & $0.95 \leq \mathrm{NFI} \leq 1$ & $0.90 \leq \mathrm{NFI} \leq 0.95$ &, 907 \\
NNFI & $0.97 \leq \mathrm{NNFI} \leq 1$ & $0.95 \leq \mathrm{NNFI} \leq 0.97$ &, 947 \\
$\mathrm{CFI}$ & $0.97 \leq \mathrm{CFI} \leq 1$ & $0.97 \leq \mathrm{CFI} \leq 1$ &, 900 \\
GFI & $0.95 \leq \mathrm{GFI} \leq 1$ & $0.90 \leq \mathrm{GFI} \leq 0.95$ &, 930 \\
$\chi 2 / \mathrm{df}$ & $1<\chi 2 / \mathrm{df}<2$ & $2<\chi 2 / \mathrm{df}<3$ & 2,550 \\
SRMR & $0.05 \leq \mathrm{SRMR} \leq 1$ & $0.00 \leq \mathrm{SRMR} \leq 0.05$ &, 034 \\
$\mathrm{P}$ & $0.05 \leq \mathrm{p} \leq 1$ & $0.05 \leq \mathrm{p} \leq 0.05$ &, 034 \\
AGFI & $0.95 \leq \mathrm{AGFI} \leq 1$ & $0.90 \leq \mathrm{AGFI} \leq 0.95$ &, 930 \\
\hline
\end{tabular}

According to the results of the confirmatory factor analysis conducted for validity studies of the language scale of fraction teaching, the ratio of $\chi^{2} / \mathrm{df}$ calculated according to the model from the fit indexes of the proposed model is considered as a perfect fit when the ratio is below 3. This ratio is $\chi^{2} / \mathrm{df} 2,550$ for this study. In other words, it presents a perfect fit. The evidence of the model having a perfect fit is the values for GFI being .930, AGFI being .904, CFI being .900, RMR p being 034, and RMSEA being .061. By calculating NFI as .907, it is understood that the model presents an acceptable good fit close to perfect.

Moreover, they indicated that if the value of Chi-square, which is divided by degree of freedom, is smaller than 3 , it is and must be statistically insignificant $(p=.00)$. When the DFA findings are evaluated by taking this information as a reference, it can be considered acceptable according to NFI indexes, and it has been found that it perfectly conforms to GFI, AGFI, CFI, IFI, RMR, RMSEA, and $\chi 2$ / df indexes. It can be noted that the factor structure is close to being perfect and have a good fittingness, according to these findings.

\section{PATH Diagram}

Path diagram is schema obtained as a result of the analysis in the structural equilibrium model. This schema, $\mathrm{t}$ value, factor loadings, variances, and goodness of fit values can be seen. Values that are not present in this analysis can be seen in the Amos program.

The path diagram for the proposed structural model is shown below. 


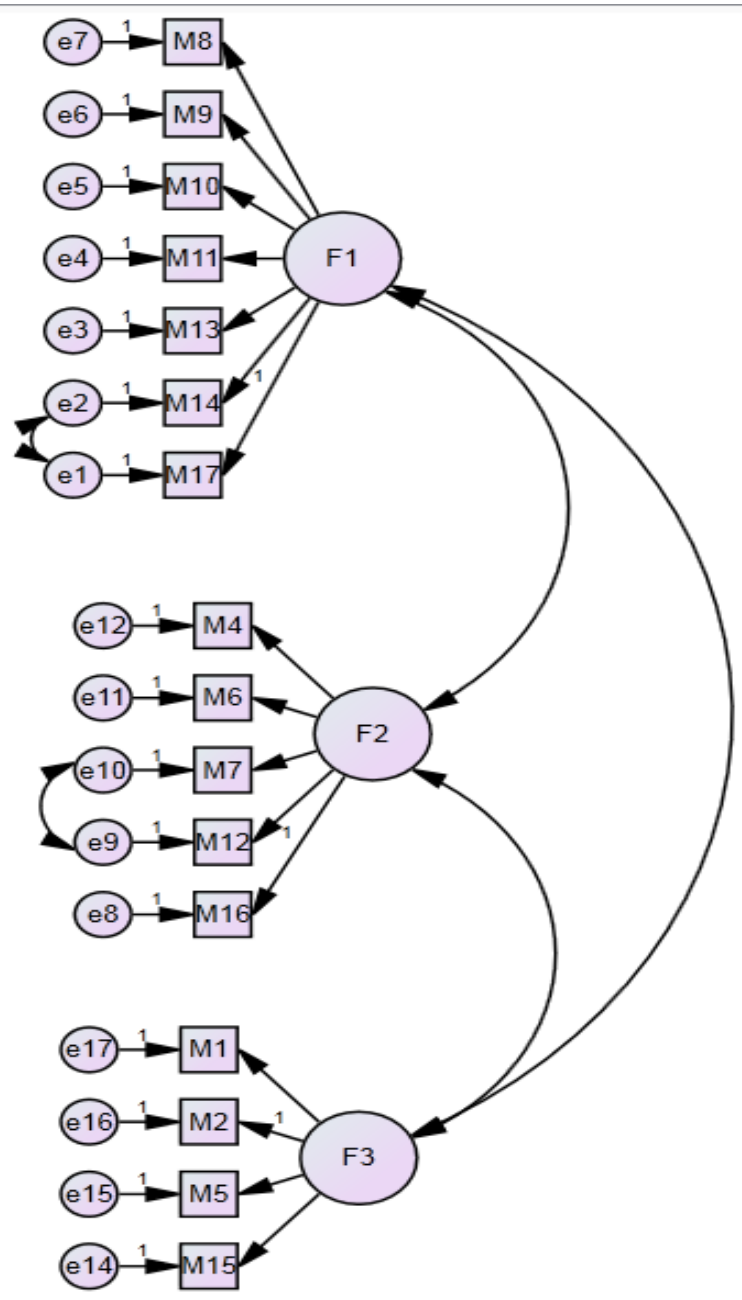

Figure 2. Path Diagram

The Path diagram for the proposed structural model is consistent with analyses made and proves that the items are loaded with correct factors. From this point of view, it can be said that analyses move in compliance with the model.

\section{Discussion}

Mathematics is known as one of the most difficult courses to accomplish. The fact that students do not well understand the nature of mathematics is one of the reasons for this situation (Yeşildere, 2015). One of the basic elements of learning concepts and information about mathematics and adopting mathematical thinking is the correct use of the language in the field. The use of language plays an important role in understanding the concepts introduced to students (Lansdell, 1999). The strong relation between numeracy and language is relatively more evident in primary school children's academic development. This relation seems to be well known to almost all elements of early symbolic numeracy and not precise to man or woman components of the symbolic machine, as Purpura and Ganley (2014) located that language abilities accounted for significant variance in predicting almost all early numeracy skills. MLSFT scale can be used in fraction teaching for elementary school students to reveal their abilities and the skills of teachers in terms of mathematical language used. 
At the end of the study, it was determined that the MLSFT scale was sufficient both in terms of validity and reliability. The scale is divided into three sub-factors as "student approach", "use of fraction language", "symbol use-written expression". The internal reliability coefficient of each factor was determined as .898, .896, and .900, and the reliability coefficient (Cronbach's Alpha) of the entire scale was found to be .898 .

\section{Conclusions}

The analysis of the collected data shows that this study has enough features in the method section to measure an acceptable structure in terms of model-data compatibility. Accordingly, the scale can be used to evaluate elementary school students and their teachers regarding the use of fractional language in fraction teaching. The main reason for developing a mathematical language scale in fraction teaching is that fractions are one of the most difficult and abstract subjects in mathematics for students to comprehend (Light and Snow, 2012; Misquitta, 2011). Moreover, fractions and decimals are among the subjects that primary school students have difficulty in understanding (Sulak, Ardahan, Avcioglu, and Sulak, 1999). From this point of view, this area should be paid attention to. It can also be argued that variance in applying the measurement instrument to different levels of education in the future (secondary school, high school, and university). Access to broader and larger samples will lead to an increase in the generalization of the results of this study.

It is important to use mathematical language in mathematics teaching as it will contribute to students' learning. The development of early mathematical knowledge is critical to the development of later mathematics skills. Researchers have emphasized the importance of including a mathematical language component in general mathematics instruction (Chard et al., 2008; Clements and Sarama, 2011). It has been argued that improving mathematical language enhances children's mathematical knowledge. Specifically, it is believed that understanding mathematical vocabulary allows children to understand the meaning of mathematical discussions with parents and teachers as well as within instructional learning activities (Purpura, Napoli, Wehrspann, and Gold, 2017).

In his study conducted to reveal the misconceptions of the third-grade students about understanding the relationship between the fraction's model, symbol, and verbal expression (reading), Pesen (2007) found that students had many misconceptions about these three concepts. The misconceptions of the verbal expression of fractions indicate that students do not learn mathematics language well. Yavuz-Mumcu (2015) stated that students failed to perceive comma as a reagent in the decimal fractions and ignored using them. They placed it in the place of the division line and were unable to understand the digit value. Therefore, it is understood that students are faced with many mistakes because they cannot read and understand the fractional language of decimals sufficiently. MLSFT scale with primary school children was designed to improve both mathematical knowledge and mathematical language. Given the significant amount of specific variance accounted for in early numeracy with the aid of mathematical language, the language element of mathematics may be one of those complex aspects accounting for significant variance in later literacy skills. As such, in addition, research of how language-associated competencies influence mathematics improvement and the way mathematics capabilities may additionally affect language development are needed.

All of the analysis results show that the measurement instrument's level of validity and reliability is sufficient, and it can explain the structure determined by three factors. In 
conclusion, it can be stated that the importance given to the use of language in fractional teaching in mathematics will increase, and more attention will be paid to education.

\section{References}

Andrew, D. P. S., Pedersen, P. M. ve McEvoy, C. D. (2011). Research methods in sport management. Champaign: Human Kinetics.

Aydın, F., and Özmen, Z. M. (2012). In verbal problems, 8th grade students' ability to determine the relationship between given and desired, X. National Science and Mathematics Education Congress, Niğde University, Niğde, https://www.pegem.net/Akademi/kongrebildiri_detay.aspx ?id=135846

Aydın, S., and Yeşilyurt, M. (2007). Student's view about the language used in mathematics teaching: Electroic Journal of Social Sciences, 6(22), 90-100.

Başol, G., Çakan, M., Kan, A., Özbek, Ö.Y., Özdmir, D., and Yaşar, M. (2008). Measurement and Evaluation in Education, Ankara: Pegem Academy.

Brown, M. W., and Cudeck, R. (1993). Alternative ways of assessing model fit. edited by K. A. Bollen, J. S. Long, Testing structural equation models, 136-162. Thousand Oakes, CA: Sage.

Büyüköztürk, Ş. (2002). Factor Analysis: Basic concepts and using to development scale. Educational Administration in Theory \& Practice, 32, 470-483. http://dergipark.gov.tr/download/article-file/108451

Büyüköztürk, Ş. (2011). Data Analysis Handbook: Statistics, Research Design, SPSS Applications and Interpretation, Ankara: Pegem Academy.

Çalıkoğlu Bali, G. (2002). Language in mathematics teaching scale, Hacettepe University Journal of Education, 23, 57-61.

Çalıkoğlu Bali, G. (2003). The opinions of pre-service mathematics teachers on language in teaching mathematics. Hacettepe University Journal of Education, 25, 19-25.

Çapık, C. (2014). Use of confirmatory factor analysis in validity and reliability studies, Journal of Anatolia Nursing and Health Sciences, 17(3), 196-205.

Chard, D. J., Baker, S. K., Clarke, B., Jungjohann, K., Davis, K., and Smolkowski, K.(2008). Preventing early mathematics difficulties: the feasibility of a rigorouskindergarten mathematics curriculum. Learning Disability Quarterly, 31, 11-20.

Child, D. (2006). The essentials of factor analysis.London: Continuum.

Çimen, E. E. (2012). The planning of education and instruction process which fosters development of mathematical power. Education Sciences, 7(2), 823-839.

Clements, D. H., and Sarama, J. (2011). Early childhood mathematics intervention.Science, 333, 968-970. http://dx.doi.org/10.1126/science.120453

Coakes, S. J. (2005). SPSS: Analysis without Anguish: Version 12.0 for Windows. Melbourne: John Wiley and Sons.

Comrey, A.L., and Lee, H.L.(1992). A first course in factor analysis, Hillsdale, New Jersey: Erlbaum

David J. Purpura, Amy R. Napoli, Elizabeth A. Wehrspann \& Zachary S. Gold (2017) Causal Connections Between Mathematical Language and Mathematical Knowledge: A Dialogic Reading Intervention, Journal of Research on Educational Effectiveness, 10:1, 116-137, DOI: 10.1080/19345747.2016.1204639

Doğan, M., and Güner, P. (2012). Examination of pre-service primary school mathematics teachers' skills of understanding and using mathematics language, X. National Science and Mathematics Education Congress, Niğde University, Niğde, 29.06.2012. 
Ellerton. N. F., and Clarkson, P.C. (1996). Language factors in mathematics teaching and learning. In International handbook of mathematics education, 987-1033. Springer, Dordrecht.

Gable, R. K. (1986). Instrument Development in the Affective Domain. Boston: KluwerNijhoff Publishing.

Gawned, S. (1990). An emerging model of the language of mathematics' in J. Bickmore branded. Language in mathematics. Australian Reading Ass. Carlton. Vic.27-42.

Göktürk, B., Soylu, Y., and Göktürk, Ö. (2012). Comparison of students' views on the language used in mathematics teaching, X. National Science and Mathematics Education Congress, Niğde University, Niğde, 29.06.2012.

Güneş, G., and Gökçek, T. (2013). Determining the mathematical literacy levels of prospective teachers, Dicle University Journal of Ziya Gökalp Faculty of Education, 20, 70-79.

Hutcheson, G. D., and Sofroniou, N. (1999). The multivariate social scientist: Introductory statistics using generalized linear models. Sage.

Iş1k, C., and Kar, T. (2012). Analyzing Problems Posed by 7th Grade Students for Addition Operation with Fractions. Elementary Education Online, 11(4), 1021-1035.

Karasar, N. (2009). Scientific research methods, Ankara: Nobel Publishing.

Kaya, D., and Keşan, C. (2012). Conceptual and operational implementations for numeric section students who are a candidate for university. Journal of Research in Education and Teaching, 1(3), 347-351.

Kline, R. B. (2005). Principles and Practice of Structural Equation Modeling. NY: Guilford Publications, Inc.

Kothari, C. R. (2004). Research Methodology, New Delhi: New Age International (P) Ltd., Publishers.

Lansdell, J. M. (1999). Introducing young children to mathematical concepts: Problems with new terminology. Educational Studies, 25(3), 327-333

Marsh, H.W., and Hocevar, D. (1988). A new more powerful approach to multitraitmultimethod analyses: Application of second-order confirmatory factor analysis. Journal of Applied Psychology, 73 107-117.

Misquitta, R. (2011). A review of the literature: Fraction instruction for struggling learners in mathematics. Learning Disabilities Research \& Practice, 26 (2), 109-119.

Moseley, B. (2005). Pre-service early childhood educators' perceptions of math-mediated language. Early Childhood and Development, 16(3), 385-396.

Munro, B. H. (2005). Statistical methods for health care research (Vol. 1). Lippincott Williams \& Wilkins.

Murphy, K. R., and Davidshofer, C. O. (1998). Psychological Testing Principles and Applications. Fourth Edition. New Jersey: Prentice-Hall.

Myers, W. H. (2000). A structural equation model of family factors associated with adolescent depression Ph.D. diss., The University of Memphis.

National Council of Teachers of Mathematics (NCTM) (1989). Curriculum and evaiuation standards for school mathematics, NCTM, Reston, WA.

National Council of Teachers of Mathematics (NCTM) (2000). Principles and Standards for School Mathematics http://www.nctm.org/standards/content.aspx?id=16909s

National Council of Teachers of Mathematics. (2006). Curriculum focal points for prekindergarten through grade 8 mathematics: Aquest for coherence. Reston, VA: NCTM

National Mathematics Advisory Panel. (2008). Foundations for success. Jessup, MD: U.S. Department of Education. www.ed.gov/MathPanel. 
Noar, S. M. (2003). The role of structural equation modelling in scale development. Structural Equation Modelling: A Multidisciplinary Journal, 10 (4), 622-647.

Orton, A., and Frobisher, L. (1996). Insights into teaching mathematics. London: Cassell.

Osborne, J.W., and Costello, A.B. (2004). Sample size and subject to 1tem ratio in principal components analysis, http://pareonline.net/getvn.asp? $\mathrm{v}=9 \& \mathrm{n}=11$.

Otterburn, M.K., and Nicholson, A.R. (1976). The Language of CSE mathematics, Mathematics in School (5), 18-20.

Pesen, C. (2007). Students' Misconceptions about Fractions. Education and Science, 32 (143), 79-88.

Raiker, A. (2002). Spoken Language and Mathematics. Cambridge Journal of Education, 32(1), 45-60.

Schumacker, R. E., and Lomax, R. G. (2004). A beginner's guide to structural equation modeling. Lawrence Erlbaum Associates. Mahwah, NJ.

Şeker, H., and Gençdoğan, B. (2006). Developing measurement tools in psychology and education. Ankara: Nobel Publication Distribution.

Şimşek, Ö. F. (2007). Introduction to Structural Equation Modeling, Ankara: Ekinoks Publications.

Sinanoğlu, O. (2000). Bye-bye Turkish. Otopsi Publications. İstanbul

Singh, Y. K. (2006). Fundamental of Research Methodology and Statistics. New Delhi, New Age International (P). Ltd., Publishers.

Sipahi, B., Yurtkoru, E. S., and Çinko, M. (2010). Data analysis with SPSS in Social Sciences, İstanbul: Beta.

Sowder, J. T., and Wearne, D. (2006). What do we know about eighth-grade student achievement? Mathematics Teaching in the Middle School, 11(6), 285-293.

Soylu, Y., and Aydin, S. (2006). A study on importance of the conceptual and operational knowledge are balanced in mathematics lessons. Erzincan University Journal of Education Faculty, 8(2), 83-95.

Sulak, H., Ardahan, H. Avcıoglu, A., and Sulak, H. (1999). Diagnosing the Misconceptions of Primary and Secondary School Students in Solving Verbal Problems, Selçuk University Research Foundation Project, 1996-1997, Project No: 96/122, Konya.

Sümer, N. (2000). Structural Equation Modeling: Basic Concepts and Applications. Turkish Psychological Articles, 3(6), 49-74.

Tabachnick, B. G., and Fidell, L. S. (2001). Using multivariate analysis. California State University Northridge: Harper Collins College Publishers.

Tekindal, S. (2009). Creating a tool for measuring affective characteristics. Ankara: Pegem Academy.

Tezbaşaran, A. (1997). Likert type scale development guide. Ankara: Turkish Psychological Association Publication

Toll, S. W. M., and Van Luit, J. E. H. (2014a). Explaining numeracy development inweak performing kindergartners. Journal of Experimental Child Psychology, 124,97-111. http://dx.doi.org/10.1016/j.jecp.2014.02.001

Toptaş, V. 2015. An overview of the mathematical language, International Journal of New Trends in Arts, Sports \& Science Education, 4(1), 18-22

Walkey, F., and Welch, G. (2010). Demystifying factor analysis: How it works and how to use it. Bloomington: Xlibris, Corp.

Walsh, W. B., and Betz, N. E. (1995). Tests and Assessment. Third Edition. New Jersey: Prentice-Hall.

Wang, J., and Wang, X. (2012). Structural equation modeling: Applications using Mplus. Chicester, UK: John Wiley \& Sons Ltd. 
Wearne, D., and Kouba, V. L. (2000). Rational numbers. In E. A. Silver \& P. A. Kenney (Eds.), Results from the seventh mathematics assessment of the National Assessment of Educational Progress (pp. 163-191). Reston, VA: NCTM.

Yavuz, S. (2005). Developing a technology attitude scale for pre-service chemistry teachers, The Turkish Online Journal of Educational Technology, 4(1), 17-25.

Yavuz-Mumcu, H. (2015). Grade 6, 7, and 8 students' misconceptions about decimal fractions and their reasons, Dicle University Journal of Ziya Gökalp Faculty of Education, 24, 294-338.

Yeşildere, S. (2015). The competencies of prospective primary school mathematics teachers in using mathematical language. Boğaziçi University Journal of Education, 24(2), 6170. https://dergipark.org.tr/tr/pub/buje/issue/3824/51415

Yiğit, N., and Kurnaz, M. A. 2010. Physics attitude scale: Its development, validity, and reliability. Necatibey Faculty of Education, Electronic Journal of Science and Mathematics Education, 4(1), 29-49.

Yılmaz, V., and Çelik, H. E. (2009). Structural equation modeling-I. Ankara: Pegem academy.

Yüzerler, S., and Doğan, M. (2012). 6th and 7th grade students' ability to use mathematical language. X. National Science and Mathematics Education Congress Niğde University, Niğde, 29.06.2012. 